\title{
Retraction Note to: Chapters
}

\author{
Abderrahim Elmoataz, Olivier Lezoray, Fathallah Nouboud, \\ and Driss Mammass
}

\section{Retraction Note to: \\ Chapter "Reinstating Floyd-Steinberg: Improved Metrics for Quality Assessment of Error Diffusion Algorithms" in: Sam Hocevar and Gary Niger: Image and Signal Processing, LNCS 5099, https://doi.org/10.1007/978-3-540-69905-7_5}

\section{Retraction Note to:}

Chapter "A Novel Text-Independent Speaker Verification System Using Ant Colony Optimization Algorithm" in: Shahla Nemati, Reza Boostani, and Mohammad Davarpanah Jazi: Image and Signal Processing, LNCS 5099, https://doi.org/10.1007/978-3-540-69905-7_48

\section{For Chapter 5:}

The Editors have retracted this chapter [1] because it has come to their attention that the second author, Gary Niger, is fictitious and the affiliation of the first author, Sam Hocevar, does not appear to exist. The Editors therefore no longer have confidence in the reliability of the work presented.

Sam Hocevar has not responded to correspondence regarding the concerns raised and the retraction.

[1] Hocevar, S., Niger, G.: Reinstating Floyd-Steinberg: improved metrics for quality assessment of error diffusion algorithms. In: Elmoataz, A., Lezoray, O., Nouboud, F., Mammass, D. (eds.) Image and Signal Processing, ICISP 2008. LNCS, vol. 5099. Springer, Berlin, Heidelberg (2008). https://doi.org/10.1007/978-3-540-69905-7_5

For chapter 48:

The paper "A Novel Text-Independent Speaker Verification System Using Ant Colony Optimization Algorithm" by Shahla Nemati, Reza Boostani and Mohammad Davarpanah Jazi, starting on page 421 of this publication, has been retracted as Sect. 3 of this paper was plagiarized from the paper starting on page 12 of LNCS 4973.

The retracted version of these chapters can be found at https://doi.org/10.1007/978-3-540-69905-7_5

https://doi.org/10.1007/978-3-540-69905-7_48 